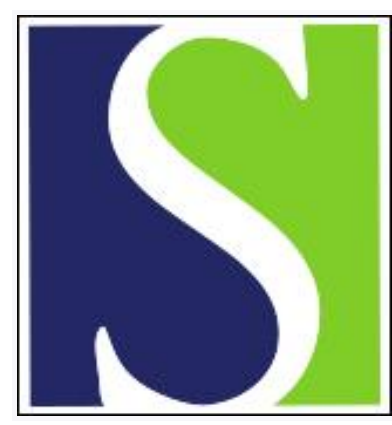

Scand J Work Environ Health 2006;32(1):51-60

https://doi.org/10.5271/sjweh.976

Issue date: 31 Feb 2006

\title{
Fertility among female hairdressers
}

by Axmon A, Rylander L, Lillienberg L, Albin M, Hagmar L

Affiliation: Department of Occupational and Environmental Medicine, University Hospital, SE-221 85 Lund, Sweden. anna.axmon@med.lu.se

Key terms: female; fertility; hair preparations; hairdresser; reproduction; spontaneous abortion

This article in PubMed: www.ncbi.nlm.nih.gov/pubmed/16539172

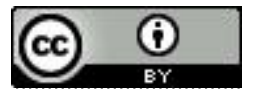




\title{
Fertility among female hairdressers
}

\author{
by Anna Axmon, PhD, ${ }^{1}$ Lars Rylander, PhD, ${ }^{1}$ Linnéa Lillienberg, PhD, ${ }^{2}$ Maria Albin, MD, ${ }^{1}$ Lars Hagmar, \\ $M D^{1}$
}

\author{
Axmon A, Rylander L, Lillienberg L, Albin M, Hagmar L. Fertility among female hairdressers. Scand J Work \\ Environ Health 2006;32(1):51-60.
}

\begin{abstract}
Objectives The study investigated whether working as a hairdresser has a negative impact on fertility, measured as time to pregnancy and miscarriage risk.

Methods Self-administered questionnaires were sent to 5289 Swedish hairdressers (response rate $50 \%$ ) and to 5299 age-matched women from the general Swedish population (response rate 54\%). Information was collected on time to pregnancy or trying time for women who had tried, but failed, to conceive at the time of the study. The outcome of the pregnancy was determined and categorized as either miscarriage or stillbirth or live birth. The hairdressers were compared with the referents with respect to these two outcomes. Within the hairdresser cohort, the effects of hair treatments, as well as physical workload and stress were investigated.

Results The hairdressers were less successful than the reference cohort in conceiving (fecundability ratio 0.91 , 95\% confidence interval 0.83-0.99). The effect was reduced after first-month conceptions were excluded, the indication being that the effect may be the result of birth control bias. Within the hairdresser cohort, a selfperceived stressful work situation seemed to prolong the time to pregnancy. No effects were found for the different chemical hair treatments. There was no cohort difference with respect to miscarriage risk (odds ratio $1.12,95 \%$ confidence interval $0.88-1.42$ ), but miscarriage risks were increased for most of the hair treatments and for self-perceived stressful work situations. However, none of these effects were statistically significant. Conclusions The present study indicates a negative impact on time to pregnancy and miscarriage risk for working as a hairdresser."
\end{abstract}

Key terms hair preparations; reproduction; spontaneous abortion.

Hairdressers are exposed on a daily basis to several chemical substances that may be hazardous to reproduction. Some animal studies support reproductive toxic effects for dyes containing agents such as 2,5-diaminotoluene and phenylenediamines (1-4), and for dibutylphthalate, which is used in hair spray (5-7).

In addition to different chemical exposures, hairdressers may be exposed to several other factors that are possibly unfavorable for reproduction, including work in a standing position (8-10) and a stressful work situation (11-15). Nevertheless, so far only a few studies on reproductive outcomes among hairdressers have been carried out (16). The results from these studies indicate an increased risk for menstrual disorders (17) and spontaneous abortions (18-20), as well as an increased risk for low birthweight (20-22), fetal growth retardation $(21,22)$, and malformations $(20,21)$ among infants born to exposed women.

Given the number of hazardous factors in the work environment of hairdressers and the results already found, it is of interest to investigate further the reproductive effects among these women. Time to pregnancy is a sensitive measure of a couple's fertility $(23,24)$, which has not yet been used in assessing reproductive health risks among hairdressers. The aim of this study was to investigate whether working as a hairdresser increases the time to pregnancy for wanted pregnancies or the risk of miscarriages.

1 Division of Occupational and Environmental Medicine and Psychiatric Epidemilogy, Institute of Laboratory Medicine, University Hospital, Lund, Sweden.

2 Section of Occupational Medicine, Institute of Internal Medicine, Sahlgrenska University Hospital, Göteborg, Sweden.

Correspondence to: Dr Anna Axmon, Department of Occupational and Environmental Medicine, University Hospital, SE22185 Lund, Sweden. [E-mail: anna.axmon@med.lu.se.] 


\section{Study population and methods}

\section{Study population and questionnaire}

In 1996, a cohort of women who had graduated from any of the 29 Swedish vocational schools for hairdressers between 1970 and 1995 and who were born in 1946 or later was established (25). For comparisons, a reference cohort of women from the Swedish general population was created. The referents were frequency matched to the hairdressers by calendar year of birth, but they were otherwise randomly selected. In 2000, the subgroups, consisting of the women in the original cohorts who were born in 1960 or later, were invited to the current study ( $73 \%$ of the hairdressers and $72 \%$ of the referents). Although the women who graduated from vocational schools for hairdressers were not necessarily working as hairdressers in 2000 , we henceforth refer to the groups of women born in 1960 or later as the hairdresser cohort and the reference cohort.

Self-administered questionnaires regarding time to pregnancy and pregnancy outcome were sent by mail to the women in the hairdresser $(\mathrm{N}=5289)$ (figure 1) and reference $(\mathrm{N}=5299)$ cohorts. The questionnaires were designed in such a way that factors that applied to pregnancy in general (eg, use of oral contraceptives prior to trying to conceive) were asked about only once and related to the time prior to when the woman started her attempts to become pregnant. Other factors that may change over time (such as smoking habits, but also including occupational exposure specific to hairdressers) were determined for each 3-month period during the year prior to conception and for each trimester during the pregnancy. From the women who never succeeded in conceiving, or were currently trying to conceive,

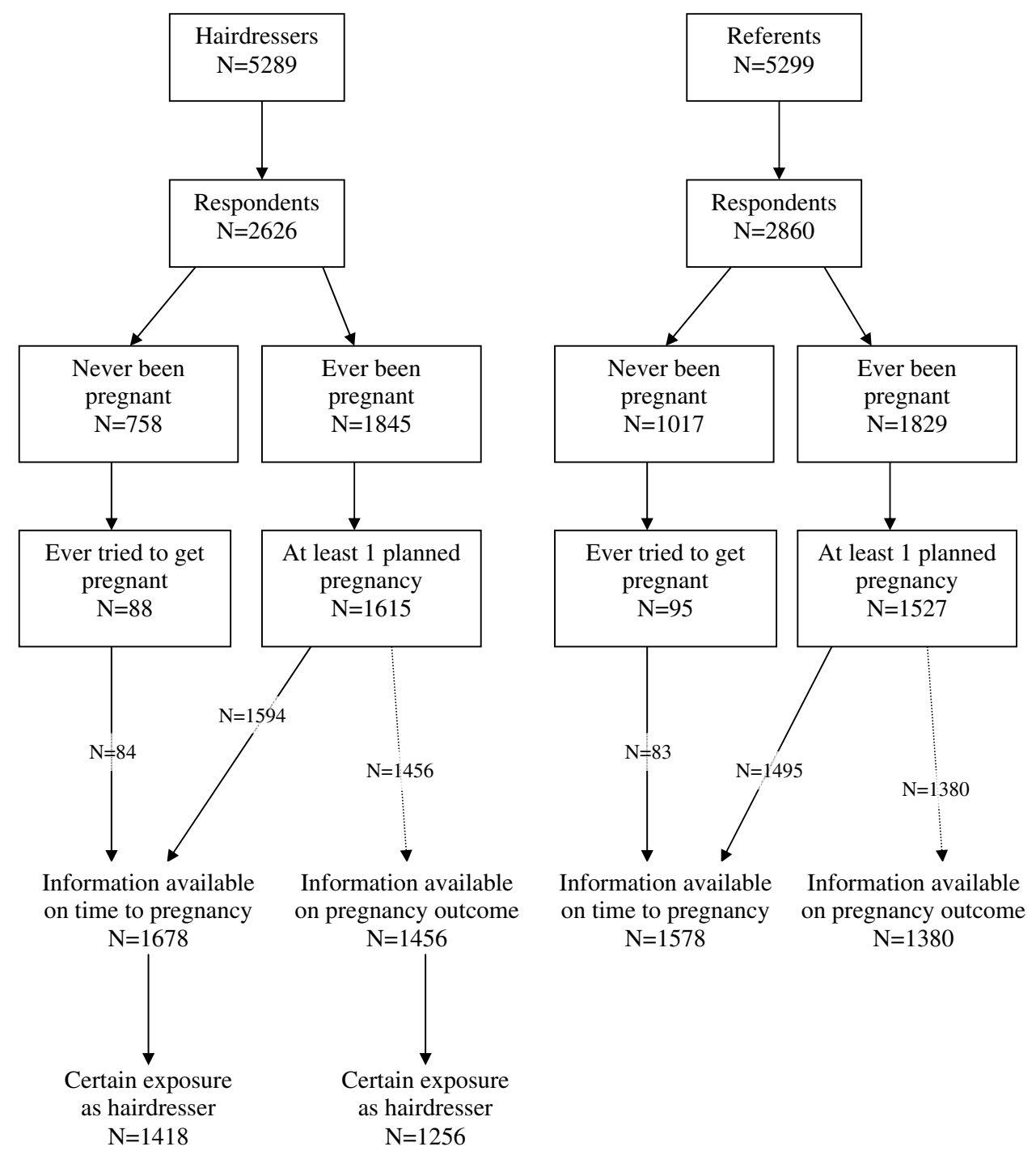

Figure 1. Women included in a study on reproductive outcomes among hairdressers. Due to missing information in some of the questionnaires, the numbers do not always add up to $100 \%$. 
information was collected for the period during which they tried to conceive. It was not specified if the answers should relate to the beginning or end of this period.

The response rates to the questionnaire were $50 \%$ $(\mathrm{N}=2626)$ and $54 \%(\mathrm{~N}=2860)$ for the hairdressers and referents, respectively (figure 1).

\section{Outcome variables}

The main outcome variable, time to pregnancy for the first planned pregnancy, was assessed by the following line of questions: "Did you become pregnant the first month of trying? If not, did you become pregnant the second month of trying? If not, in which month did you become pregnant?" With this method of inquiring about time to pregnancy, the uncertainty concerning women who conceived in their first cycle was reduced (26). However, it may have introduced other sources of error. For example, 14 hairdressers and 12 referents checked the "no" boxes for achieving pregnancy in the first or second month, but did not provide a time to pregnancy. The median recall time for time to pregnancy was 7 [1 (2.5 percentile) - 18 (97.5 percentile)] years.

The women who had never been pregnant were asked if they were, or at some point had been, trying to conceive, and, if so, for how long. These trying-times were included in the time to pregnancy analyses as censored times to pregnancy.

Miscarriage risk was used as a secondary outcome. For the women who had had at least one planned pregnancy, the outcome of the first planned pregnancy was established and classified as miscarriage, stillbirth or live birth (including multiple birth); at the same time, induced abortions ( 8 in each cohort), extra-uterine pregnancies (10 hairdressers and 8 referents), and pregnancies that were still ongoing when the women answered the questionnaire ( 87 hairdressers and 65 referents) were excluded.

In the analyses of time to pregnancy, 1678 hairdressers and 1578 referents were included (figure 1), whereas 1456 hairdressers and 1380 referents were included in the miscarriage analyses.

\section{Exposure variables}

The hairdresser cohort was compared with the reference cohort in an evaluation of the possible reproductive health risks of working as a hairdresser. In the main cohort comparisons, no concern was given to working status (hairdresser, other work, unemployed). However, as already stated, some of the women in the hairdresser cohort did not necessarily work as a hairdresser when they were trying to conceive. Nevertheless, questions on job title (for gainfully employed women only) and hairdresser work during the time when the woman tried to conceive made it possible to establish a subcohort of women who, with certainty, were exposed before and during their pregnancies. These women represented approximately $60 \%(\mathrm{~N}=1534)$ of the women in the total hairdresser cohort. Of the remaining $40 \%$, only a fourth had claimed not to have been working as a hairdresser prior to or during the pregnancy. For the other women, information was missing on whether they were working as a hairdresser during the relevant time periods, either because they were not gainfully employed during this period or they chose not to answer this question. Among the 1534 women with certain hairdresser exposure, 1418 had provided information on time to pregnancy and 1256 on pregnancy outcome (figure 1).

Within the hairdresser cohort, numbers of treatments of permanent waving, hair bleaching, oxidative haircoloring formulations, direct-reacting hair-coloring formulations (supertones), and direct nonreactive haircoloring formulations (mousse, tones), as well as the use of hair spray, were considered as measures of exposure, as was the number of hours working in a standing position, a self-perceived stressful work situation, and selfemployment (compared with being employed).

\section{Potential confounders}

The distributions of potential confounders for time to pregnancy are presented for the hairdressers and referents in table 1.

Menstrual cycle length was available only for the women who actually became pregnant, who were asked about their normal menstrual cycle length prior to the pregnancy. A small fraction of the women (3\% of the hairdressers and $4 \%$ of the referents) claimed to have very short menstrual cycles ( $<14$ days). It was assumed that these women had mistaken menstrual cycle length for menses duration, and their menstrual cycle length was set as missing.

All of the women were asked if they used any medication, vitamins, or food supplements regularly prior to or during pregnancy, and, if so, what product(s). A physician went through the list of product names and classified them as either medication or vitamin, mineral, or iron supplements. Unfortunately, it was not possible to make a distinction between use of medication and vitamins prior to and during the pregnancy.

After conception, the frequency of smokers was reduced in both the hairdresser $(\mathrm{N}=206$, ie, reduced to $18 \%)$ and reference $(\mathrm{N}=203$, ie, reduced to $19 \%)$ cohorts, as was the frequency of women who consumed alcohol [90 hairdressers (ie, reduced to 8\%), 97 referents 
Table 1. Potential confounders for the 1678 hairdressers and 1578 referents included in a study on the effect of work as a hairdresser on time to pregnancy.

\begin{tabular}{|c|c|c|c|c|c|c|c|c|}
\hline & \multicolumn{4}{|c|}{ Hairdressers } & \multicolumn{4}{|c|}{ Referents } \\
\hline & $\mathrm{N}$ & $\%$ & Median & $95 \%$ range & $\mathrm{N}$ & $\%$ & Median & $95 \%$ range \\
\hline Age when included in study (years) & . & . & 32 & $24-39$ & . & . & 33 & $23-39$ \\
\hline Age at first menstruation (years) & . & . & 13 & $10-15$ & . & . & 13 & $10-16$ \\
\hline \multicolumn{9}{|l|}{ Education } \\
\hline Elementary school (9 years) & 34 & 2 & . & . & 146 & 9 & . & . \\
\hline High school & 1490 & 90 & . & . & 884 & 57 & . & . \\
\hline College or university & 131 & 8 & & & 533 & 34 & $\cdot$ & $\cdot$ \\
\hline Age at conception (years) & & & 25 & $19-34$ & . & $\cdot$ & 25 & $19-34$ \\
\hline \multicolumn{9}{|l|}{ When starting to attempt pregnancy } \\
\hline Length of menstrual cycle (days) a & & & 28 & $23-36$ & . & . & 28 & $23-35$ \\
\hline Oral contraceptives as last contraceptive method & 1167 & 74 & $\cdot$ & $\cdot$ & 969 & 67 & $\cdot$ & $\cdot$ \\
\hline Nulliparous & 1258 & 79 & . & . & 1081 & 73 & . & . \\
\hline Heavy lifts & 388 & 29 & $\cdot$ & . & 664 & 52 & $\cdot$ & . \\
\hline \multicolumn{9}{|l|}{ Employment } \\
\hline Full-time employment & 607 & 43 & . & . & 943 & 68 & . & . \\
\hline Part-time employment & 125 & 9 & . & . & 240 & 16 & . & . \\
\hline Self-employed & 577 & 41 & $\cdot$ & . & 31 & 2 & . & . \\
\hline Housewife & 11 & 1 & . & . & 36 & 2 & . & . \\
\hline Student & 50 & 4 & . & . & 105 & 6 & . & . \\
\hline Unemployed & 18 & 1 & . & . & 56 & 4 & . & . \\
\hline Other & 13 & 1 & $\cdot$ & . & 29 & 2 & . & $\cdot$ \\
\hline Irregular workhours ${ }^{b}$ & 251 & 21 & . & . & 509 & 45 & . & . \\
\hline Nightshift b & 18 & 2 & . & . & 86 & 8 & . & . \\
\hline Workplace smoking b & 468 & 39 & . & . & 355 & 34 & . & . \\
\hline Smoking (cigarettes/day for smokers) & 408 & 30 & 10 & $2-20$ & 348 & 27 & 10 & $2-20$ \\
\hline Partner's smoking (cigarettes/day for smokers) & 260 & 20 & 15 & $2-30$ & 248 & 20 & 15 & $3-30$ \\
\hline Alcohol consumption (yes) & 846 & 62 & $\cdot$ & $\cdot$ & 720 & 57 & $\cdot$ & $\cdot$ \\
\hline Partner's alcohol consumption (yes) & 1050 & 81 & . & . & 875 & 73 & . & . \\
\hline Use medication regularly ${ }^{c}$ & 96 & 6 & . & . & 127 & 8 & . & . \\
\hline Taking vitamins, minerals or iron supplements ${ }^{c}$ & 401 & 24 & . & . & 318 & 20 & . & . \\
\hline
\end{tabular}

a Excluding women with menstrual cycles 14 days or shorter.

${ }^{b}$ Only among those employed or self-employed.

c Information only available for the entire period from the year before conception to delivery.

(ie, reduced to 9\%)]. The other factors were similar to the corresponding prepregnancy factors (data not shown).

\section{Potential effect modifiers}

The hairdressers were asked about the ventilation in the salon where they were working prior to and during their pregnancy or when they were trying to conceive. Specifically, they were asked about passive ventilation and the absence-presence of general ventilation and local exhaust ventilation. The different ventilation methods were grouped so that no ventilation or passive ventilation only was regarded as low ventilation, the presence of either general or local exhaust ventilation was regarded as medium ventilation, and the presence of both general and local exhaust ventilation was regarded as high ventilation (if either general or local exhaust ventilation was present, passive ventilation was disregarded). All of the results concerning hair treatments were stratified on the level of ventilation that was used in the salon.

\section{Nonrespondents and missing information}

The date of birth was known for all of the women who received the questionnaire, and it was found that the respondents and nonrespondents to the questionnaire did not differ in age (median year of birth 1969 for both the hairdressers and the referents). Data from the Swedish Medical Birth Registry was available for all of the women who gave birth between 1973 and 1994, which made it possible to compare the nonrespondents with the respondents with respect to several reproductive outcomes. Note that the information from the Medical Birth Registry was not used in any of the other analyses. Among the nonrespondents, there were slightly more women included in the Medical Birth Registry than among the respondents ( $40 \%$ versus $37 \%$ of the hairdressers and $38 \%$ versus $35 \%$ of the referents). The smoking habits of the women were not recorded in the Medical Birth Registry until 1982. Among the women who gave birth after this date, there was a lower fraction of nonsmokers among the nonrespondents than among the respondents (66\% versus $74 \%$ among the 
hairdressers and $63 \%$ versus $74 \%$ among the referents).

\section{Statistics}

Information on exposure, potential confounders, and effect modifiers was collected. For the women whose time to pregnancy was shorter than 12 months, the information corresponding to the time when they started their attempts to become pregnant was used. For women whose time to pregnancy was longer than 12 months, the information concerning the 10th to 12th months prior to conception was used. For the women who were censored at 2 months, the information concerning the 3 months prior to conception was used, since we did not know the exact time to pregnancy. In the miscarriage analyses, the information concerning the first trimester of the pregnancy was used.

For each of the specific hairdresser exposures, the hairdresser cohort was split into two subgroups-those who had exposure below the median and those who had exposure equal to or above the median. These two subgroups were compared with the reference cohort. Since it is fair to assume that the level of ventilation in the salon affects the exposure levels, analyses were also carried out that included only hairdressers with no or low ventilation.

All of the data were analyzed using SPSS (SPSS Inc, Chicago, IL, USA).

A logistic regression of the survival data was carried out to estimate the effects of the cohort affiliation and hairdresser exposure on time to pregnancy. The rationale for using the logistic regression model comes from the discrete linear logistic model (27), which is applicable when survival time is discrete (28). For each comparison, a fecundability ratio was calculated from the odds ratio (OR) of each time interval (1-1.9, 2-2.9, etc). The model assumption that odds ratios are similar for each time interval was checked using an interaction term between time and interval. Fecundability ratios are similar to effect estimates obtained from an analysis based on the proportional hazards model when the event rates are small in each interval and the follow-up period is relatively short (28). Note that since the fecundability ratio measures positive events (wanted pregnancies), a value of less than one indicates a prolonged time to pregnancy as compared with that of the reference group.

To avoid interference from medical treatment for infertility (24), we censored time to pregnancy at 12 months (113 hairdressers and 91 referents). Furthermore, time to pregnancy for the women who had currently (59 hairdressers and 65 referents) or previously (23 hairdressers and 18 referents) been trying to conceive were censored at 12 months, at the time they filled out the questionnaire or at the time they stopped trying to conceive. Moreover, the 14 hairdressers and 12 referents who had checked the "no" boxes for achieving pregnancy in the first or second month, but did not give a time to pregnancy were included in the time-to-pregnancy analysis, but censored at 2 months. All of the women who stated that their pregnancy was a result of medical treatment (84 hairdressers and 69 referents) were included in the analysis. For these women, it was assumed that the time to pregnancy was longer than 12 months even if time to pregnancy was missing, since this is normally the earliest time point when medical treatment is introduced. In order to control bias due to birth control failure (29), we repeated the analyses after the exclusion of data on first-cycle pregnancies.

Odds ratios calculated using a logistic regression were used to estimate miscarriage risks.

Multivariate analyses comparing the hairdressers with the referents were carried out that included the confounders in table 1 . When selecting confounders for the multivariate analyses, we used the stepwise method suggested by Greenland (30). Variables were entered into the model if they changed the effect estimate by $\geq 10 \%$ and excluded if exclusion changed the effect estimate by $<5 \%$.

\section{Results}

\section{Time to pregnancy}

The fraction of women who needed more than 12 months to conceive was slightly higher among the hairdressers $(\mathrm{N}=113 ; 7 \%)$ than among the referents $(\mathrm{N}=91$; $6 \%$ ). When time to pregnancy as a continuous variable was considered, the hairdressers were less successful in conceiving than the referents (fecundability ratio $=0.91$, 95\% confidence interval $0.83-0.99$ ). The median time to pregnancy was, however, 2 months in both groups (excluding women who were censored at 2 months; see the statistics section). The decreased conception rate seemed in part to be an effect of birth control bias. When an analysis was carried out with the women who got pregnant the first month of trying [515 hairdressers $(31 \%)$ and 554 referents (36\%)] excluded, the difference between the cohorts was reduced (fecundability ratio $0.96,95 \% \mathrm{CI} 0.87-1.07)$. The results changed less than $10 \%$ when the potential confounders from table 1 were included in the bivariate models. Thus no adjusted effect estimates are presented. When the subcohort of hairdressers who were exposed with certainty compared with the reference cohort (fecundability ratio $=0.95,95 \%$ CI $0.87-1.03$ ), the results were similar to those found when the entire hairdresser cohort was compared with the reference cohort. 
The specific exposure analyses were performed only for the hairdressers who were exposed with certainty prior to their pregnancy $(\mathrm{N}=1418)$. Due to missing exposure data, the number of women included in the analyses differed slightly (table 2).

On the basis of the results from the cohort comparison, it was to be expected that the specific exposure analyses would also show reduced fecundability. Indeed, for some of the exposures investigated (setting permanent waves, oxidative hair-coloring formulations, direct-reacting hair dyes, working in a standing position, self-employment, and stressful work situation), there were indications of a dose-response relation between exposure and fecundability (table 2). Adjusting for potential confounders changed the effect estimates by less than $10 \%$.

Ventilation level was considered as no-low $(\mathrm{N}=348)$ or medium-high $(\mathrm{N}=754)$. When the analyses regarding specific exposure were restricted to hairdressers with no or low ventilation, the effects were slightly larger than when all the hairdressers were included in the analyses. However, this subgroup was rather small, and hence the confidence intervals were relatively wide.

\section{Miscarriages}

The number of women whose first planned pregnancy ended in a miscarriage was $157(11 \%)$ in the hairdresser

Table 2. Time to pregnancy for the women working as hairdressers when starting their attempts to conceive. Fecundability ratios for the women with exposure above or below the median compared with those of the referents from the general population are presented with their $95 \%$ confidence intervals $(95 \% \mathrm{Cl})$.

\begin{tabular}{|c|c|c|c|c|c|c|}
\hline \multirow[t]{2}{*}{ Exposure } & \multicolumn{3}{|c|}{ All hairdressers } & \multicolumn{3}{|c|}{ Hairdressers with low or no ventilation } \\
\hline & $\begin{array}{l}\text { Women with } \\
\text { exposure } \\
\text { information } \\
\text { (N) }\end{array}$ & $\begin{array}{l}\text { Fecunda- } \\
\text { bility } \\
\text { ratio }\end{array}$ & $95 \% \mathrm{Cl}$ & $\begin{array}{l}\text { Women with } \\
\text { exposure } \\
\text { information } \\
\text { (N) }\end{array}$ & $\begin{array}{l}\text { Fecunda- } \\
\text { bility } \\
\text { ratio }\end{array}$ & $95 \% \mathrm{Cl}$ \\
\hline \multicolumn{7}{|l|}{ Setting permanent waves } \\
\hline Referents & 1578 & 1.00 & .. & 1578 & 1.00 & .. \\
\hline Below median (4 treatments/week) & 493 & 0.91 & $0.80-1.04$ & 146 & 0.84 & $0.68-1.05$ \\
\hline Above median (4 treatments/week) & 581 & 0.86 & $0.76-0.97$ & 172 & 0.83 & $0.68-1.01$ \\
\hline \multicolumn{7}{|l|}{ Hair bleaching } \\
\hline Referents & 1578 & 1.00 &.. & 1578 & 1.00 & .. \\
\hline Below median (4 treatments/week) & 530 & 0.88 & $0.78-0.99$ & 170 & 0.81 & $0.66-0.99$ \\
\hline Above median (4 treatments/week) & 536 & 0.89 & $0.79-1.01$ & 142 & 0.86 & $0.69-1.07$ \\
\hline \multicolumn{7}{|l|}{ Oxidative hair-coloring formulations } \\
\hline Referents & 1578 & 1.00 & .. & 1578 & 1.00 & .. \\
\hline Below median (2 treatments/week) & 535 & 0.94 & $0.83-1.06$ & 169 & 0.86 & $0.70-1.05$ \\
\hline Above median (2 treatments/week) & 522 & 0.83 & $0.73-0.94$ & 140 & 0.83 & $0.66-1.03$ \\
\hline \multicolumn{7}{|l|}{ Direct-reacting hair dyes } \\
\hline Referents & 1578 & 1.00 &.. & 1578 & 1.00 & .. \\
\hline Below median (3 treatments/week) & 452 & 0.92 & $0.80-1.05$ & 146 & 0.86 & $0.69-1.07$ \\
\hline Above median (3 treatments/week) & 585 & 0.86 & $0.76-0.96$ & 158 & 0.82 & $0.67-1.01$ \\
\hline \multicolumn{7}{|l|}{ Nonreactive dyes or tones } \\
\hline Referents & 1578 & 1.00 &.$\cdot$ & 1578 & 1.00 & .. \\
\hline Below median (2 treatments/week) & 558 & 0.89 & $0.79-1.01$ & 170 & 0.85 & $0.69-1.03$ \\
\hline Above median (2 treatments/week) & 431 & 0.90 & $0.79-1.03$ & 116 & 0.95 & $0.75-1.20$ \\
\hline \multicolumn{7}{|l|}{ Hair spray } \\
\hline Referents & 1578 & 1.00 &.. & 1578 & 1.00 & .. \\
\hline Below median (30 treatments/week) & 472 & 0.89 & $0.79-1.02$ & 148 & 0.81 & $0.65-1.00$ \\
\hline Above median (30 treatments/week) & 540 & 0.87 & $0.77-0.99$ & 154 & 0.84 & $0.68-1.04$ \\
\hline \multicolumn{7}{|l|}{ Working in a standing position } \\
\hline Referents & 1578 & 1.00 & .. & 1578 & 1.00 & .. \\
\hline Below median (8 hours/day) & 334 & 0.97 & $0.82-1.15$ & 58 & 0.97 & $0.70-1.35$ \\
\hline Above median (8 hours/day) & 927 & 0.84 & $0.76-0.93$ & 249 & 0.77 & $0.65-0.91$ \\
\hline \multicolumn{7}{|l|}{ Self-employment } \\
\hline Referents & 1578 & 1.00 & .. & 1578 & 1.00 & .. \\
\hline Employed hairdressers & 732 & 0.90 & $0.80-1.01$ & 126 & 0.86 & $0.68-1.07$ \\
\hline Self-employed hairdressers & 577 & 0.82 & $0.73-0.93$ & 192 & 0.77 & $0.63-0.93$ \\
\hline \multicolumn{7}{|l|}{ Stressful work situation } \\
\hline Referents & 1578 & 1.00 &.. & 1578 & 1.00 & .. \\
\hline Hairdressers without stress & 472 & 1.00 & $0.87-1.15$ & 102 & 0.88 & $0.68-1.13$ \\
\hline Hairdressers with stress & 819 & 0.78 & $0.70-0.87$ & 205 & 0.71 & $0.59-0.86$ \\
\hline
\end{tabular}


cohort and 135 (10\%) (OR 1.12, 95\% CI 0.88-1.42) in the reference cohort. The effect estimate changed less than $10 \%$ when the potential confounders were included in the bivariate models. Similar results were found for the subgroup of hairdressers who had hairdresser exposure with certainty, and when women whose pregnancies were not determined by a pregnancy test (21 hairdressers and 19 referents) were excluded (data not shown).

The analyses of specific exposures were carried out only with the 1256 hairdressers who were exposed with certainty during pregnancy. Due to missing exposure data, the number of women in the different analyses varied slightly (table 3 ).

The crude odds ratios indicated dose-response relations between exposure and miscarriage for setting permanent waves, hair bleaching, oxidative hair-coloring formulations, nonreactive dyes, hair spray, and working in a standing position (table 3). However, all of these risks disappeared when adjustment was made for potential confounders. Hairdressers with a self-perceived stressful work situation were more likely to experience a miscarriage, but also this risk disappeared when potential confounders were adjusted for.

\section{Discussion}

Our study gives some indications of a prolonged time to pregnancy among hairdressers when they are compared with women from the general population.

Table 3. Exposure variables and number of first planned pregnancy miscarriages for Swedish women who were working as hairdressers during their first planned pregnancy. The odds ratios (ORs) were adjusted for year of birth, age at conception, performance of heavy lifts, use of oral contraceptives prior to pregnancy, menstrual cycle length prior to pregnancy, partner's smoking habits, and workplace smoking and presented with $95 \%$ confidence intervals $(95 \% \mathrm{CI})$.

\begin{tabular}{|c|c|c|c|c|c|}
\hline Exposure & $\mathrm{N}$ & Crude OR & $95 \% \mathrm{Cl}$ & Adjusted OR & $95 \% \mathrm{Cl}$ \\
\hline \multicolumn{6}{|l|}{ Setting permanent waves } \\
\hline Referents & 1381 & 1.00 &.. & 1.00 & .. \\
\hline Below median (4 treatments/week) & 419 & 1.06 & $0.73-1.52$ & 0.72 & $0.45-1.17$ \\
\hline Above median (4 treatments/week) & 487 & 1.25 & $0.90-1.73$ & 0.88 & $0.57-1.37$ \\
\hline \multicolumn{6}{|l|}{ Hair bleaching } \\
\hline Referents & 1381 & 1.00 &.. & 1.00 & .. \\
\hline Below median (4 treatments/week) & 458 & 1.08 & $0.76-1.53$ & 0.77 & $0.48-1.21$ \\
\hline Above median (4 treatments/week) & 441 & 1.26 & $0.90-1.77$ & 0.79 & $0.50-1.24$ \\
\hline \multicolumn{6}{|l|}{ Oxidative hair-coloring formulations } \\
\hline Referents & 1381 & 1.00 &.. & 1.00 & .. \\
\hline Below median (2 treatments/week) & 488 & 1.05 & $0.75-1.48$ & 0.75 & $0.48-1.18$ \\
\hline Above median (2 treatments/week) & 399 & 1.35 & $0.96-1.91$ & 0.88 & $0.56-1.40$ \\
\hline \multicolumn{6}{|l|}{ Direct-reacting hair dyes } \\
\hline Referents & 1381 & 1.00 &.. & 1.00 & .. \\
\hline Below median (3 treatments/week) & 396 & 1.30 & $0.92-1.85$ & 0.87 & $0.54-1.40$ \\
\hline Above median (3 treatments/week) & 474 & 1.11 & $0.79-1.56$ & 0.79 & $0.51-1.23$ \\
\hline \multicolumn{6}{|l|}{ Nonreactive dyes or tones } \\
\hline Referents & 1381 & 1.00 &.. & 1.00 & .. \\
\hline Below median (2 treatments/week) & 481 & 1.14 & $0.82-1.60$ & 0.74 & $0.47-1.15$ \\
\hline Above median (2 treatments/week) & 356 & 1.23 & $0.85-1.78$ & 0.95 & $0.59-1.53$ \\
\hline \multicolumn{6}{|l|}{ Hair spray } \\
\hline Referents & 1381 & 1.00 &.. & 1.00 & .. \\
\hline Below median (30 treatments/week) & 417 & 0.98 & $0.68-1.42$ & 0.65 & $0.39-1.07$ \\
\hline Above median (30 treatments/week) & 438 & 1.24 & $0.89-1.75$ & 0.93 & $0.61-1.43$ \\
\hline \multicolumn{6}{|l|}{ Working in a standing position } \\
\hline Referents & 1381 & 1.00 & .. & 1.00 & .. \\
\hline Below median (8 hours/day) & 259 & 1.03 & $0.66-1.60$ & 0.69 & $0.40-1.19$ \\
\hline Above median (8 hours/day) & 744 & 1.17 & $0.88-1.57$ & 0.89 & $0.61-1.30$ \\
\hline \multicolumn{6}{|l|}{ Self-employment } \\
\hline Referents & 1381 & 1.00 & .. & 1.00 & .. \\
\hline Employed hairdressers & 626 & 1.26 & $0.93-1.70$ & 0.85 & $0.57-1.28$ \\
\hline Self-employed hairdressers & 470 & 1.07 & $0.76-1.52$ & 0.78 & $0.50-1.21$ \\
\hline \multicolumn{6}{|l|}{ Stressful work situation } \\
\hline Referents & 1381 & 1.00 & .. & 1.00 & .. \\
\hline Hairdressers without stress & 381 & 0.73 & $0.48-1.12$ & 0.57 & $0.34-0.95$ \\
\hline Hairdressers with stress & 668 & 1.46 & $1.10-1.93$ & 1.01 & $0.70-1.46$ \\
\hline
\end{tabular}


However, it cannot be ruled out that this, in part, is an effect of birth control bias. Within the hairdresser cohort, a self-perceived stressful work situation, but not chemical exposure based on the number of hair treatments per week, was found to decrease fertility by means of prolonging the time to pregnancy.

There was no increased miscarriage risk among the hairdressers versus women from the general population. However, within the hairdresser cohort, a self-perceived stressful work situation indicated an increased risk of miscarriage. A raised, but not statistically significant, miscarriage risk was found for most of the hair treatments.

Fertility was measured using time to pregnancy, as well as frequency of miscarriages. It has been found that time to pregnancy is a useful tool when reproductive effects are being assessed (23) and that data can be collected retrospectively (23) by using self-administered questionnaires (31). A major criticism concerning retrospective time-to-pregnancy studies has been the exclusion of women who never conceived. By asking all women who had never been pregnant if they had ever tried to become pregnant, we were able to include women who had tried to conceive but so far had failed to do so.

For the women who had yet to become pregnant, information was collected for the entire period when they tried to conceive. This period could cover several years, and thus the quality of these data, and especially that of the dichotomous variables, may be biased when compared with that of women whose time to pregnancy ended in a pregnancy. However, the fraction of women who had not yet conceived was very low $(5 \%$ in each cohort), and the impact on the fecundability estimates should therefore be slight, at most.

Even though information concerning time to pregnancy is probably recalled correctly by the women (23), the recall concerning work-related factors in the hairdresser cohort was not necessarily as good. A subsample of the hairdresser cohort had previously been examined with respect to reliability for self-reported exposure (25). It was found that, if a misclassification was introduced by the questionnaire, it probably resulted in underestimations of the effects of specific exposure. A further concern with respect to exposure classification is that it is a crude one, based on the number of treatments per week, and no information was collected on whether the hairdressers were using gloves when applying chemicals to the customers' hair. Personal and stationary measurements in Norwegian hairdresser salons have shown low mean air concentrations of isopropanol, ethanol, and ammonia, whereas phenylenediamine and diamionotolouene were nondetectable (32). The exposure level was significantly lower in salons with local exhaust ventilation than in those with no ventilation.
It is probable that the conditions have been similar in Sweden. However, even though almost all hairdressers in Sweden have used gloves when mixing and applying hair dyes, not all have used new gloves for every treatment, and only few have used gloves when applying permanent waving (Birgitta Meding, personal communication, 2004). Thus dermal uptake may still have occurred.

Nineteen of the salons were visited by occupational hygienists, and ventilation velocities were measured. A comparison with the answers in the self-administered questionnaire showed that the hairdressers knew if there was only passive ventilation. However, there was a tendency for the hairdressers in small salons to overestimate the ventilation levels, whereas the hairdressers in big salons underestimated the ventilation levels. Although this difference may have lead to some misclassification, it was not likely to be associated with the outcomes time to pregnancy and miscarriage.

In addition to the use of chemical treatments and work in a standing position, we examined self-employment and a self-perceived stressful working situation. With respect to self-employment, the risk of misclassification should be minimal. However, a self-perceived stressful work situation was determined by the use of a single yes-no question and, therefore, must be considered as a very crude measure of stress.

The response rate to the questionnaire was rather low. However, we had substantial information regarding both the reproductive and lifestyle factors of the nonrespondents to enable satisfactory nonrespondent analyses. The results from these analyses speak against any sizeable selection bias due to none or only small differences in the occurrence of potential confounders. Moreover, the minor discrepancies between the respondents and nonrespondents were nondifferential between the hairdressers and the referents.

When miscarriage risk was assessed, the information related to the first trimester of pregnancy was used. The reason for using this variable, rather than a longterm exposure, was the a priori idea that miscarriages related to hairdresser exposure would be the result of an effect on the fetus, rather than, for example, damaged ovarian function. Furthermore, available data do not support long-term biological half-times for the potential hazardous chemicals in the hairdresser work environment.

We chose to use women from the general Swedish population as the reference group. This choice may have resulted in some of the referents being exposed to other, to us unknown, reproductive hazards in worklife. Indeed, some of the referents may have been exposed to chemicals and work conditions that were similar to those of the hairdressers. This possibility is unavoidable when the general population is used as a comparison group and may lead to the true risk differences 
being attenuated. On the other hand, selecting "unexposed groups" from the general population for comparisons may result in uncontrolled bias from differences in socioeconomic and lifestyle factors.

When all pregnancies (first month conceptions also) were included, there was approximately a $10 \%$ less chance of a hairdresser conceiving than the referents each month (fecundability ratio 0.91 ). The analyses carried out within the reference cohort (33), which was a representative sample of Swedish women, found that this effect on fertility is of the same magnitude as, for example, the effect of smoking (yes; no) (fecundability ratio 0.93 ) or ageing 2 years (fecundability ratio 0.90 ).

To not be able to conceive can, in itself, cause stress. Therefore, when the effect of stress on fertility is investigated, it is difficult to determine whether stress has led to decreased fertility, or, in fact, the decreased fertility is the cause of the stress. In our current study we assessed stress as a self-perceived stressful work situation, which should not have been affected by a possible failure to conceive.

It has been suggested that a possible association between stress and reproductive outcomes, specifically miscarriages, relates to the fact that women who experience high levels of stress are more likely to be smokers (34). In the hairdresser cohort, the fraction of women who reported a stressful work situation was similar between the nonsmokers (64\%) and smokers (66\%).

The results from the analyses of time to pregnancy in our study are consistent with those of a previous study on hairdressers, in which an increased risk for subfertility (time to pregnancy $>12$ months) was found (20). The results regarding chemical exposure and miscarriage risk lend some support to the results of previous studies in which an increased risk of miscarriages was found for hairdressers and cosmetologists $(18,20)$.

Our study gives some indication of a prolonged time to pregnancy among hairdressers, which could possibly be explained by the fact that these women experience a very stressful work situation. There was no strong support for the hypothesis that the chemicals handled by hairdressers affect time to pregnancy. No increased miscarriage risk was found for the hairdressers when they were compared with the referents. However, the miscarriage risks were increased for most of the hair treatments, as well as for self-perceived stressful work situation, although none of the effects were statistically significant.

\section{Acknowledgments}

This work was financed by grants from the Swedish Council for Working Life and Social Research, the
Medical Faculty at Lund University, and Region Skåne. None of the authors have any competing interests.

The study was approved by the Ethics Committee at Lund University.

\section{References}

1. Inouye M, Murakami U. Teratogenicity of 2,5-diaminotoluene, a hair-dye constituent, in mice. Food Cosmet Toxicol. 1977;15:447-51.

2. Marks TA, Gupta BN, Ledoux TA, Staples RE. Teratogenic evaluation of 2-nitro-p-phenylenediamine, 4-nitro-o-phenylenediamine, and 2,5-toluenediamine sulfate in the mouse. Teratology. 1981;24:253-65.

3. Picciano JC, Morris WE, Wolf BA. Evaluation of the teratogenic potential of the oxidative dyes 6-chloro-4-nitro-2aminophenol and o-chloro-p-phenylenediamine. Food Chem Toxicol. 1984;22:147-9.

4. Burnett CM, Goldenthal EI. Multigeneration reproduction and carcinogenicity studies in Sprague-Dawley rats exposed topically to oxidative hair-colouring formulations containing pphenylenediamine and other aromatic amines. Food Chem Toxicol. 1988;26:467-74.

5. Foster PM, Mylchreest E, Gaido KW, Sar M. Effects of phthalate esters on the developing reproductive tract of male rats. Hum Reprod Update. 2001;7:231-5.

6. Gray LE Jr, Ostby J, Furr J, Price M, Veeramachaneni DN, Parks L. Perinatal exposure to the phthalates DEHP, BBP, and DINP, but not DEP, DMP, or DOTP, alters sexual differentiation of the male rat. Toxicol Sci. 2000;58:350-65.

7. Nagao T, Ohta R, Marumo H, Shindo T, Yoshimura S, Ono H. Effect of butyl benzyl phthalate in Sprague-Dawley rats after gavage administration: a two-generation reproductive study. Reprod Toxicol. 2000;14:513-32.

8. McDonald AD, McDonald JC, Armstrong B, Cherry NM, Cote R, Lavoie J, et al. Fetal death and work in pregnancy. Br J Ind Med. 1988;45:148-57.

9. Henriksen TB, Hedegaard M, Secher NJ, Wilcox AJ. Standing at work and preterm delivery. Br J Obstet Gynaecol. 1995;102:198-206.

10. Mozurkewich EL, Luke B, Avni M, Wolf FM. Working conditions and adverse pregnancy outcome: a meta-analysis. Obstet Gynecol. 2000;95:623-35.

11. Fenster L, Waller K, Chen J, Hubbard AE, Windham GC, Elkin E, et al. Psychological stress in the workplace and menstrual function. Am J Epidemiol. 1999;149:127-34.

12. Hjollund NH, Jensen TK, Bonde JP, Henriksen TB, Andersson AM, Kolstad HA, et al. Distress and reduced fertility: a follow-up study of first-pregnancy planners. Fertil Steril. 1999;72:47-53.

13. Hedegaard M. Life style, work and stress, and pregnancy outcome. Curr Opin Obstet Gynecol. 1999;11:553-6.

14. Hatch MC, Figa-Talamanca I, Salerno S. Work stress and menstrual patterns among American and Italian nurses. Scand J Work Environ Health. 1999;25(2):144-50.

15. Bashour H, Abdul Salam A. Psychological stress and spontaneous abortion. Int J Gynaecol Obstet. 2001;73:179-81.

16. Kersemaekers WM, Roeleveld N, Zielhuis GA. Reproductive disorders due to chemical exposure among hairdressers [review]. Scand J Work Environ Health. 1995;21:325-34.

17. Blatter BM, Zielhuis GA. Menstrual disorders due to chemi- 
cal exposure among hairdressers. Occup Med (Lond). 1993;43:105-6.

18. John EM, Savitz DA, Shy CM. Spontaneous abortions among cosmetologists. Epidemiology. 1994;5:147-55.

19. Vaughan TL, Daling JR, Starzyk PM. Fetal death and maternal occupation. An analysis of birth records in the State of Washington. J Occup Med. 1984;26:676-8.

20. Kersemaekers WM, Roeleveld N, Zielhuis GA. Reproductive disorders among hairdressers. Epidemiology. 1997;8:396-401.

21. Rylander L, Axmon A, Toren K, Albin M. Reproductive outcome among female hairdressers. Occup Environ Med. 2002;59:517-22.

22. Rylander L, Källén B. Reproductive outcomes among hairdressers. Scand J Work Environ Health. 2005;31(3):212-7.

23. Joffe M. Feasibility of studying subfertility using retrospective self reports. J Epidemiol Community Health. 1989;43:268-74.

24. Baird DD, Wilcox AJ, Weinberg CR. Use of time to pregnancy to study environmental exposures. Am J Epidemiol. 1986;124:470-80.

25. Albin M, Rylander L, Mikoczy Z, Lillienberg L, Dahlman Höglund A, Brisman J, et al. Incidence of asthma in female Swedish hairdressers. Occup Environ Med. 2002;59:119-23.

26. Weinberg C. Reproductive epidemiology. In: Rothman K,
Greenland S, editors. Modern epidemiology. Philadelphia (PA): Lippincott-Raven; 1998. p 585-608.

27. Cox D. Regression models and life tables. JR Stat Soc. 1972;34:187-220.

28. Hosmer D, Lemeshow S. Applied logistic regression. New York (NY): John Wiley \& Sons; 1989.

29. Weinberg CR, Baird DD, Wilcox AJ. Sources of bias in studies of time to pregnancy. Stat Med. 1994;13:671-81.

30. Greenland S. Modeling and variable selection in epidemiologic analysis. Am J Public Health. 1989;79:340-9.

31. Zielhuis GA, Hulscher ME, Florack EI. Validity and reliability of a questionnaire on fecundability. Int J Epidemiol. 1992;21:1151-6.

32. Hollund BE, Moen BE. Chemical exposure in hairdresser salons: effect of local exhaust ventilation. Ann Occup Hyg. 1998;42:277-82.

33. Axmon A, Rylander L, Albin M, Hagmar L. Factors affecting time to pregnancy. Hum Reprod. Epub 2006 Jan 12.

34. Nelson DB, Grisso JA, Joffe MM, Brensinger C, Shaw L, Datner E. Does stress influence early pregnancy loss? Ann Epidemiol. 2003;13:223-9.

Received for publication: 19 January 2005 